\title{
Anomalous Variability in Antarctic Sea Ice Extents During the 1960s With the Use of Nimbus Data
}

\author{
David W. Gallaher, G. Garrett Campbell, and Walter N. Meier
}

\begin{abstract}
The Nimbus I, II, and III satellites provide a new opportunity for climate studies in the 1960s. The rescue of the visible and infrared imager data resulted in the utilization of the early Nimbus data to determine sea ice extent. A qualitative analysis of the early NASA Nimbus missions has revealed Antarctic sea ice extents that are significant larger and smaller than the historic 1979-2012 passive microwave record. The September 1964 ice mean area is $19.7 \times 10^{6} \mathrm{~km}^{2} \pm 0.3 \times 10^{6} \mathrm{~km}^{2}$. This is more the $250,000 \mathrm{~km}^{2}$ greater than the $19.44 \times 10^{6} \mathrm{~km}^{2}$ seen in the new 2012 historic maximum. However, in August 1966 the maximum sea ice extent fell to $15.9 \times 10^{6} \mathrm{~km}^{2} \pm 0.3 \times 10^{6} \mathrm{~km}^{2}$. This is more than $1.5 \times 10^{6} \mathrm{~km}^{2}$ below the passive microwave record of $17.5 \times 10^{6} \mathrm{~km}^{2}$ set in September of 1986. This variation between 1964 and 1966 represents a change of maximum sea ice of over $3 \times 10^{6} \mathrm{~km}^{2}$ in just two years. These inter-annual variations while large, are small when compared to the Antarctic seasonal cycle.
\end{abstract}

Index Terms-Antarctic sea ice, historic data, Nimbus.

\section{INTRODUCTION}

$\mathbf{S}$ EA ice extent data from multi-channel passive microwave sensors provided one of the longest-running climate records from satellites in the form of the sea ice extent index [1]. However, while the more than 30 -year record is now long enough for typical climate-scale change, it is still relatively short. Even adding in the Nimbus V single-channel Electrically Scanning Microwave Radiometer (ESMR) data extends the record by only another 6 years and that data is not as complete or consistent [2]. Earlier data are only available from operational ice charts that are of variable quality and do not cover all ice-covered regions. This was particularly true in the Antarctic, where there were few ice charts before 1972. This paper presents Antarctic sea ice estimates for winter 1964 and 1966 derived from early Nimbus satellite data as an initial step towards creating Earth Science Data Records of sea ice in the 1960s. This record has the potential to significantly extend the passive microwave record. The Nimbus visible and near infrared data, unlike the passive microwave data, sense clouds

Manuscript received September 30, 2012; revised January 22, 2013 and April 26, 2013; accepted May 04, 2013. Date of publication June 25, 2013; date of current version March 14, 2014. This work was supported under NASA SubContract NNG08HZ07C.

D. W. Gallaher and G. G. Campbell are with the National Snow and Ice Data Center, University of Colorado, Boulder, CO 80309 USA.

W. N. Meier is with the National Snow and Ice Data Center, University of Colorado, Boulder, CO 80309 USA. He is also with the NASA Goddard Space Flight Center, Greenbelt, MD 20771 USA.

Color versions of one or more of the figures in this paper are available online at http://ieeexplore.ieee.org.

Digital Object Identifier 10.1109/JSTARS.2013.2264391 (very frequent in the polar regions), which may obscure much of the surface for days at a time. Satellite visible imagery is useful $65^{\circ}$ north to $65^{\circ}$ south latitude year round. Beyond those latitudes, visible light data generally limited to the summer periods when there is substantial sunlight. Finally, interpreting visible/infrared imagery is more difficult as there are no robust automated algorithms like those that have been developed for passive microwave imagery [1], [3]. Nonetheless, as discussed below, methods have been developed to obtain monthly composites of sea ice extent from the Nimbus data.

\section{BACKGROUND}

While early satellite missions during the 1960 s collected significant amounts of data, little of it was analyzed at the time. The limited use of the 1960s data was generally not due to the quality of the raw data, but rather because of the limited processing capability and digital archiving systems available in that era. Nimbus I, launched in August 1964, began a sequence of experimental satellites built by NASA to develop instruments to collect information about the weather (the concept of collecting time series satellite climatology was generally not considered at the time). Although the instrument and tape recorder only lasted three weeks (28 August-22 September) for Nimbus I, it was fortuitous that the measurements occurred in September during the likely Arctic ice minimum extent and Antarctic maximum extent. The early Nimbus satellites carried the High Resolution Infrared Radiometer (HRIR) and the Advanced Vidicon Camera System (AVCS) or the Image Dissector Camera System data (IDCS).

The Nimbus HRIR Instrument (Nimbus I, II, and III) used a lead Selenide $(\mathrm{PbSe})$ detector to detect infrared radiation to a precision of $\pm 1^{\circ} \mathrm{K}$ in the 3.4- and 4.2-micron bands. The Nimbus HRIR data, provides global coverage for the period from 1964 to 1972. This newly available data, in conjunction with Nimbus IV, V, and 1970s imagery from scanning radiometer, infrared and visible sensors on U.S. Department of Defense Meteorological Satellite Program (DMSP) platforms, could potentially extend the length of the climate record at the poles by $50 \%$ from the passive microwave 1979-2012 time series [4]. Interestingly, the Nimbus I HRIR data has been recovered from the original data tapes and likely is the oldest satellite-based digital temperature data available anywhere. Nimbus II collected data from 15 May 1966 to 18 January 1969. Nimbus III collected data from 14 April 1969 to 22 January 1970. These data acquisition time frames happen to include the period when the Arctic sea ice minimums and Antarctic maximums occur. Nimbus I did not reach full orbit altitude of $1100 \mathrm{~km}$ due to a short second-stage burn, resulting in an 
eccentric $429 \mathrm{~km}$ by $937 \mathrm{~km}$ orbit [5]. The lower orbit resulted in higher spatial resolution data with little overlap between images on each orbit. The coverage with Nimbus II in 1966 was better because of the higher observational altitude $(1100 \mathrm{~km})$ and $20 \%$ overlap between images, however the data are noisier. Nimbus III IDCS images $(1100 \mathrm{~km})$ cover a wider extent and the images have significantly better dynamic range and overlap.

The AVCS used video technology to collect snap shots of the reflected radiance from the Earth every 91 seconds. The instrument description can be found in the Nimbus User Guides [6]. Navigation of the images is based upon the orbit elements, time of measurement and geometry of the AVCS cameras. Although most images include a gray scale bar for calibration, variations in the camera sensitivity on the satellite and digital-to-analog data capture processes make it difficult to construct a "calibrated" radiance from the data. In addition, the data are, at best, 4-bit resolution so fine details of clouds are not evident.

\section{METHODS}

There are three primary steps in obtaining sea ice extent from the recovered data: 1) conversion and navigation correction of the HRIR digital files recovered by the NASA Goddard Space Flight Center (GSFC); 2), digitization, georectification and quality control of film images data from AVCS and IDCS held by the NOAA National Climatic Data Center; and 3) calculation of monthly composite sea ice extents from the recovered data.

It was critical to recover both the HRIR data as well as the visible AVCS/IDCS imagery data since the HRIR provided nighttime views and AVCS daytime views of the globe. The AVCS visible light data is being used to validate the HRIR sea ice extents. The value of the HRIR data lies with the fact that during the dark polar winter months the HRIR data is the only available source. In the case of Nimbus II, the HRIR tape recorder lasted nearly three months longer (15 November 1966) than the AVCS tape recorder (31 August 1966).

The GSFC recovered and rescued thousands of Nimbus HRIR digital data tapes. The recovery process involved using specially-developed tape drives, tape baking, bit detection and processing techniques to read the 800 bpi, 7-track tapes [7]. The ongoing analysis of HRIR data for sea ice detection is seen in Fig. 1. The original Tape Archive Program (TAP format) uncorrected (spatially) data from Nimbus I, II and III are now available from GSFC. NSIDC will be releasing NetCDF corrected versions of this HRIR data in mid-2013.

The digitization of the AVCS $35 \mathrm{~mm}$ film and IDCS 70 mm film was done at NSIDC. A Kodak HR500 high-speed film scanner digitized all the images with 8-bit resolution (the original AVCS film was 4-bit) to ensure complete data capture. 12,000 images from Nimbus I (Fig. 2(a), 2(b)), 120,000 images from Nimbus II and 50,000 images from Nimbus 3 were scanned. The scanner was calibrated to the grey scale on the images. All scanning was performed using consistent fixed parameters determined by the calibration to avoid any bias in the data capture. A human-augmented custom software application documented each image, recording the time and center points. This provided navigation accuracy of about $\pm 25 \mathrm{~km}$. A manual feature identification technique was developed to identify the ice boundary. About 1000 Nimbus I images were reviewed

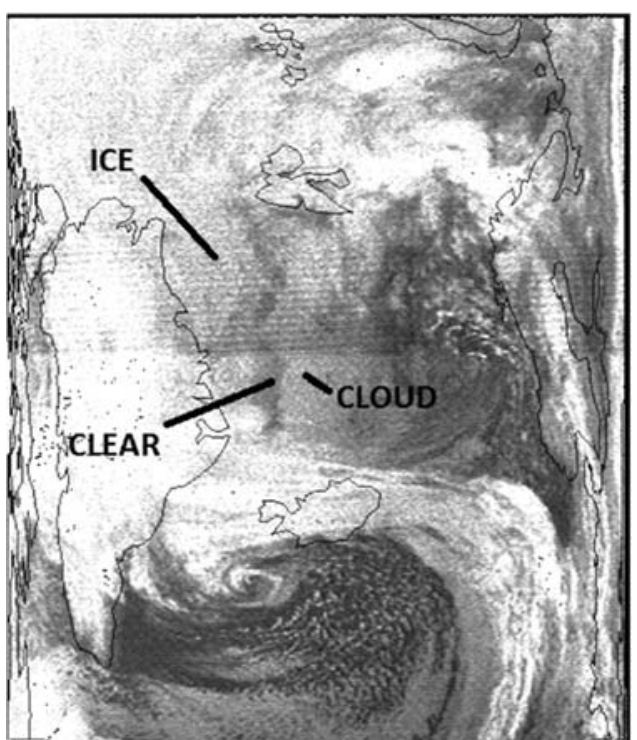

Fig. 1. Nimbus II, November 13, 1966, high resolution infrared radiometer with possible sea ice edge.

and an ice edge was identified on about half of those images. About 4000 images were reviewed from Nimbus II to create four months of ice extents displayed in Table I.

The Nimbus II data was analyzed by dividing Antarctica into $2^{\circ}$ longitude bins and averaging the observed ice extents for each bin. There were many bins with no measured values, especially the months of May and June 1966. For short gaps (up to $4^{\circ}$ longitude) values were interpolated from adjacent values. For larger gaps the SSMI climatology was substituted for the missing bins. The adjacent interpolation method was used for July and August but as there were no large gaps, and substituting SSMI values was not required for these months. The percent complete values for bins are determined before interpolation or substitution. The ice extent standard deviation is based on the average standard deviation of the ice edge latitude in each $2^{\circ}$ longitude bin from all suitable images within the bin. The standard deviation of the edge estimates reflect three factors: 1) spatial variability within the $2^{\circ}$ longitude region, 2) temporal variability within the month, and 3 ) uncertainties in the ice edge location detected in the images.

There is considerable correlation between bin measurements so it is not reasonable to translate the uncertainty in the bin averages directly into the uncertainty of the mean extents. The high correlation in bin values leads to significantly fewer than 180 independent bins. A reasonable assumption is that there are 20 independent bin regions with a one-sigma range of area. This uncertainty does not include systematic errors, which might arise from navigation errors. Qualitatively one can summarize the results as saying the May is similar to the SSM/I climatology, June and July are larger than SSM/I mean and August is lower than SSM/I climatology.

\section{ERROR ANALYSIS}

The uncertainties in determining a sea ice extent from this early data are primarily tied to the difficulty in distinguishing homogeneous clouds from homogeneous ice. Fortunately, ice 


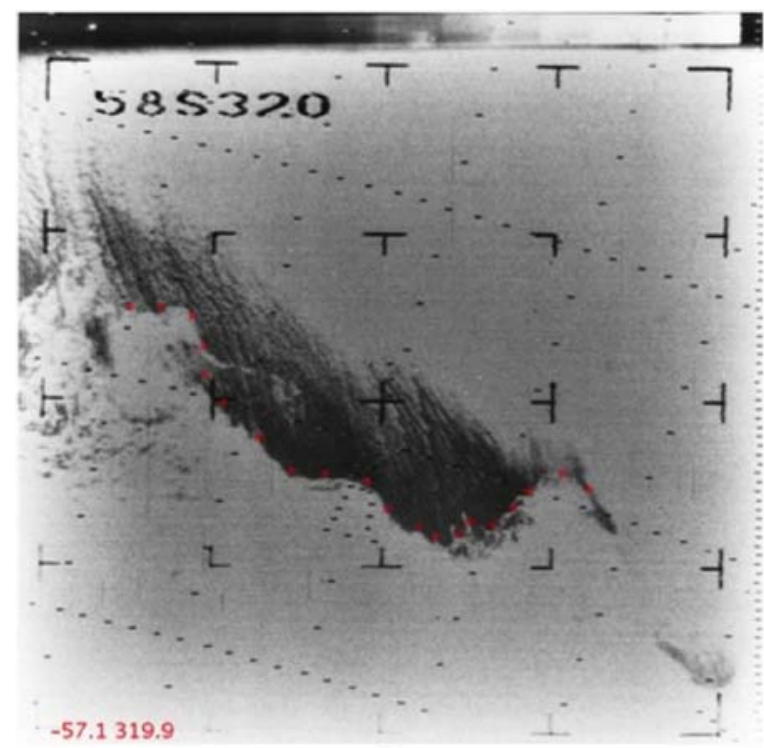

(a)

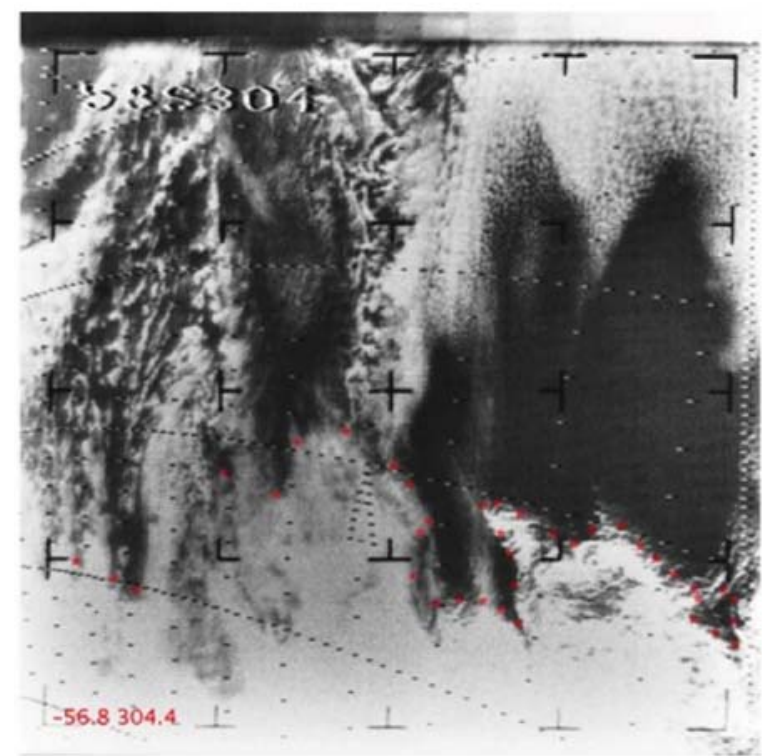

(b)

Fig. 2. a: Sample Nimbus I image September 1964 with a distinct sea ice boundary. The red marks show our manual ice edge recordings. These locations are used in the average ice extent determination. b: Sample Nimbus I image September 1964 with a less distinct sea ice boundary. The red marks show our manual ice edge recordings. These locations are used in the average ice extent determination.

edges generally appear different than cloud edges. Additionally, clouds tend to move faster than sea ice enabling edge detection when utilizing multiple images of the same location. Another difficulty in ice edge determination is the lack of independent sources of sea ice edge data in the Antarctic during the 1960s. The analysis of Arctic sea ice extent agrees very well with the historic sea ice charts from the 1960s (where the data overlaps) giving further credibility to the project results.

In an effort to create an automated ice detection method, a determination of ice extent was done by remapping and compositing the minimum brightness for all the images to derive a clear-sky radiance. This gives a qualitative impression of the location of the ice edge and provides an independent validation of the ice extent [8], but because of variations in the calibration, the project did not succeed in using the composited image for an automatic ice edge analysis. For the Nimbus II data a similar verification technique was developed. An estimated ice edge is calculated from a running 11-day minimum brightness composite for the images with an obvious sea ice edge during August 1966 (Fig. 3). Visually, it shows a solid match between the average manual ice edge and the composite minimum brightness image. There are some pixels with anomalous brightness (noise) in the image, which is why the method is not suitable for an automatic ice detection scheme, but it is useful for a qualitative evaluation of the manual analysis. It may be possible to minimize the noise by modifying ice edge techniques developed for synthetic aperture radar data with high speckle noise [9], allowing a direct estimate from the minimum brightness composite, but that is beyond the scope of this study.

\section{Antarctic Sea Ice Extent Estimates, 1964 vs. 1966}

The focus of this paper is on the comparison of anomalous maximum sea ice extents from September 1964 (Nimbus I) and August 1966 (Nimbus II) using AVCS visible imagery. Early analysis of the 1969 AVCS data indicates a return to less anomalous conditions.

\section{A. Antarctic Extent 1964}

Antarctic sea ice extent for 1964 was calculated from the Nimbus I imagery, as described in [10]. The 1964 satellite data provide fairly complete coverage over the Antarctic, allowing the ice edge to be clearly seen in most areas in at least one image over the three weeks. This provides a reasonably robust estimate of sea ice extent for the period, though some uncertainty results from the variation of the ice edge location during the time period. The Nimbus I data had at most eight images of any area in the three weeks of data collection, so it was difficult to distinguish homogeneous clouds and homogeneous ice. As illustrated in Fig. 4, the manual sea ice analysis focused on the ice margin. The analyzed ice edge locations were used in the average ice extent determination, making the assumption that locations continent-ward of the edge were ice-covered (i.e., $>15 \%$ concentration sea ice). Comparing modern SSM/I and AVHRR visible light records could further test this assumption, however this was beyond the project scope.

Fig. 5 shows the mean and minimum and maximum ice edges for September 1964, from an average in $2^{\circ}$ longitude bins. That is, all the individual latitudes falling in a longitude bin were averaged with the range recorded. Missing bins were filled with an interpolation from nearby good measurements to make the full area average up to $4^{\circ}$. For larger gaps, as found in May and June 1966, SSM/I climatology values were substituted for the missing values. For comparison the SSM/I 1979-2000 median climatology is plotted. Qualitatively, the Nimbus ice edge is often north of the passive microwave results [4] suggesting more ice than the climatology. The ice area inside the mean edge is $19.7 \times 10^{6} \mathrm{~km}^{2} \pm 0.3 \times 10^{6} \mathrm{~km}^{2}$. The uncertainty is based on the difference between the minimum and maximum area observed. Areas of the small polynyas were not subtracted, to better match the lower resolution of the passive microwave record, which can only resolve very large open water areas 
TABLE I

Antarctic 1966 Sea Ice Extent Based Manual Analysis of Nimbus AVCS Visible Images. Estimates From Images Were Composited Into a Single Extent Estimate Within a $2^{\circ}$ Longitude Bin (180 Bins Total). The Bins Were Classified as Having "High Quality" Images (I.E., IMAges Where the ICE Edge Was Clearly Apparent) and "Medium Quality" Images (I.E., Images Where There Were Ambiguities About the ICE Edge LoCations). Bins That Did Not Have Images or OnLy had “Low Quality” Images Were Filled With InTERPolated Edge Estimates From SurRounding Bins

\begin{tabular}{|l|c|l|c|c|c|}
\hline Month & $\begin{array}{c}\text { Nimbus Antarctic Ice } \\
\text { extent based only } \\
\text { on high quality bins } \\
\text { and interpolation ( } \pm \\
1 \text { st. dev. range } \\
\text { within bins) }\end{array}$ & $\begin{array}{l}\text { Nimbus Antarctic } \\
\text { Ice extent based on } \\
\text { high and medium } \\
\text { quality bins and } \\
\text { interpolation ( } \pm 1 \\
\text { st. dev. range } \\
\text { within bins) }\end{array}$ & $\begin{array}{c}\text { \% of bins } \\
\text { with high } \\
\text { quality } \\
\text { edge } \\
\text { estimates }\end{array}$ & $\begin{array}{c}\text { Ice edge } \\
\text { standard } \\
\text { deviation } \\
\text { for high } \\
\text { quality } \\
\text { bins }\end{array}$ & $\begin{array}{c}1979-2000 \mathrm{SSM} / \mathrm{I} \\
\text { climatology ice } \\
\text { extent and one st. } \\
\text { dev. range over the } \\
\text { climatology period }\end{array}$ \\
\hline May & $\mathrm{N} / \mathrm{A}$ & $10.7 \pm 0.2 \times 10^{6} \mathrm{~km}^{2}$ & $\mathrm{~N} / \mathrm{A}$ & $\mathrm{N} / \mathrm{A}$ & $10.3 \pm 0.56 \times 10^{6} \mathrm{~km}^{2}$ \\
\hline June & $14.3 \pm 0.4 \times 10^{6} \mathrm{~km}^{2}$ & $14.8 \pm 0.3 \times 10^{6} \mathrm{~km}^{2}$ & 75 & 0.81 & $13.3 \pm 0.40 \times 10^{6} \mathrm{~km}^{2}$ \\
\hline July & $16.4 \pm 0.5 \times 10^{6} \mathrm{~km}^{2}$ & $16.4 \pm 0.4 \times 10^{6} \mathrm{~km}^{2}$ & 98 & 1.05 & $15.8 \pm 0.30 \times 10^{6} \mathrm{~km}^{2}$ \\
\hline August & $15.9 \pm 0.4 \times 10^{6} \mathrm{~km}^{2}$ & $16.1 \pm 0.4 \times 10^{6} \mathrm{~km}^{2}$ & 99 & 0.76 & $17.5 \pm 0.22 \times 10^{6} \mathrm{~km}^{2}$ \\
\hline
\end{tabular}

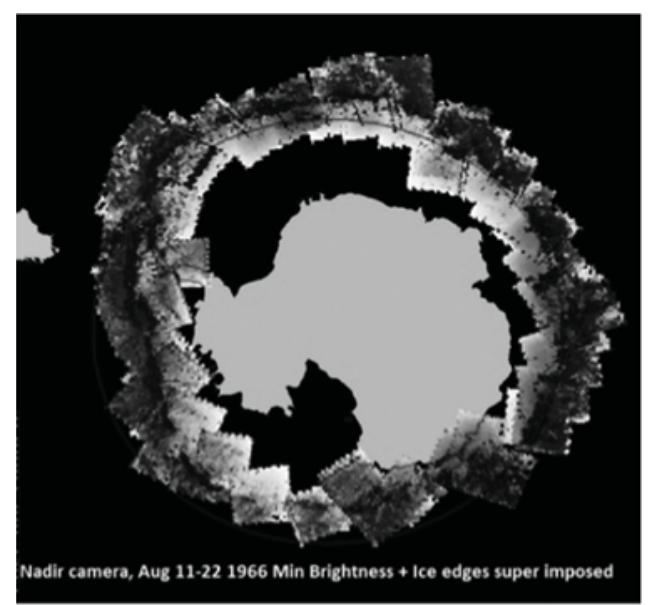

Fig. 3. Minimum AVCS brightness for the last week of August 1966 for images with obvious sea ice edges. Superimposed is the sea ice edge (black line) from the manual analysis.

within the ice edge. Notice that the $30^{\circ} \mathrm{E}$ and $90^{\circ} \mathrm{E}$ scallops appear in both data sets. There are no corroborating ship or aircraft measurements in 1964 so this is a stand-alone measurement that cannot be directly validated against comparison data. However, the estimate is consistent with Predoehl 1966 [11], which was estimated from the same Nimbus I raw data.

To put this ice extent number in context, the time variation of the passive microwave observations [1] from 1979 to 2010 are shown in Fig. 6. The range of the passive microwave in each year is the mean \pm 1 standard deviation of the daily area values for each September. September 1964 Nimbus I sea ice estimate is the largest Antarctic sea ice extent ever observed by satellites [12]. September 1964 Arctic extent was also estimated by Meier et al. [10]. The estimate is near the 1979-2000 climatological average and analyzed ice edge locations are consistent with other Arctic estimates in 1964 based on operational ice charts.

\section{B. Antarctic Extent 1966}

Coverage of Nimbus II AVCS images for the Antarctic for 1966 was fairly complete but the film record ends on August 31 so a direct comparison with the 1964 estimate from Nimbus

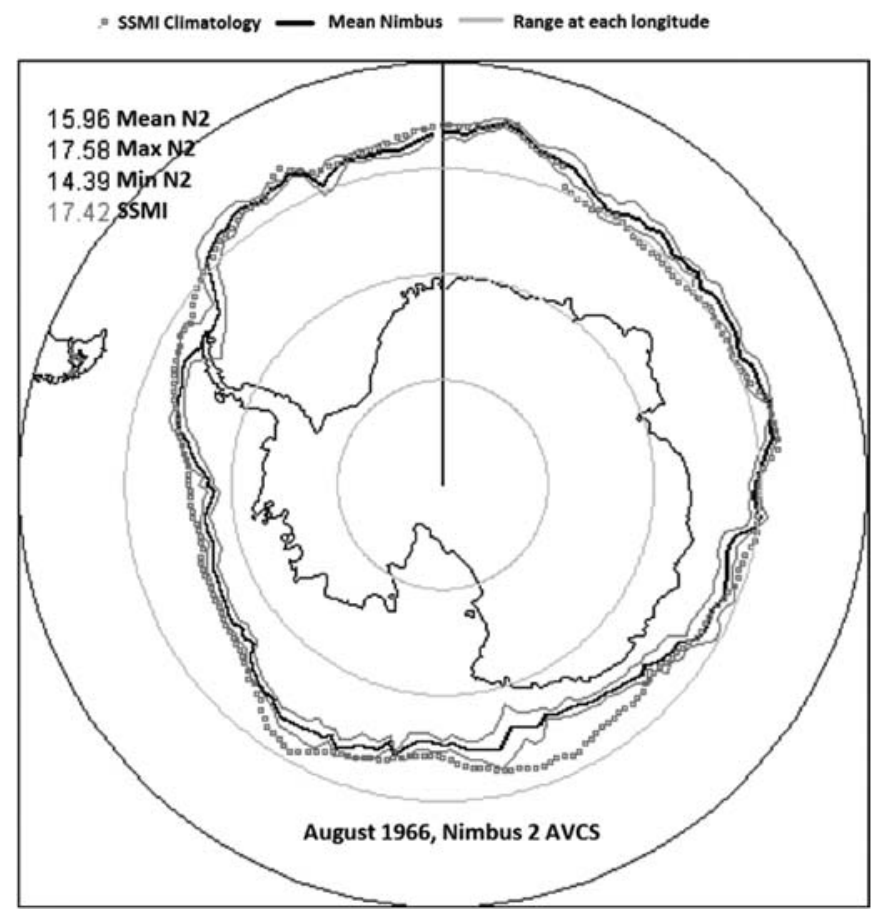

Fig. 4. Mean Antarctic ice edges Nimbus I with the range of minimum and maximum observed ice extent. The grey dashed line is the SSM/I climatology from 1978 to 2000 .

I is not possible. The manual analysis procedure for AVCS images was improved by establishing a quality indicator $(2=$ best, $1=$ usable but uncertain) for the ice edges. Fig. 6 shows the locations of ice edges for the whole month of August 1966 from the best and useable quality locations. This August 1966 data is then compared to the passive microwave 1979-2000 climatological ice extent for August. The results for May 1966 had higher uncertainty because images often lacked clean ice edges. For both May and June there were longitudes with no ice edge detection, leading to further uncertainty. The ice extent estimates for June, July and August, based on images with clean ice edges, are $14.6 \times 10^{6} \mathrm{~km}^{2}, 16.4 \times 10^{6} \mathrm{~km}^{2}$ and $15.9 \times 10^{6} \mathrm{~km}^{2}$, respectively. The 1966 June and July ice extents are just slightly below the minimal historic values for the sea ice extent relative to the passive microwave record [4], [12], [13]. However, the 


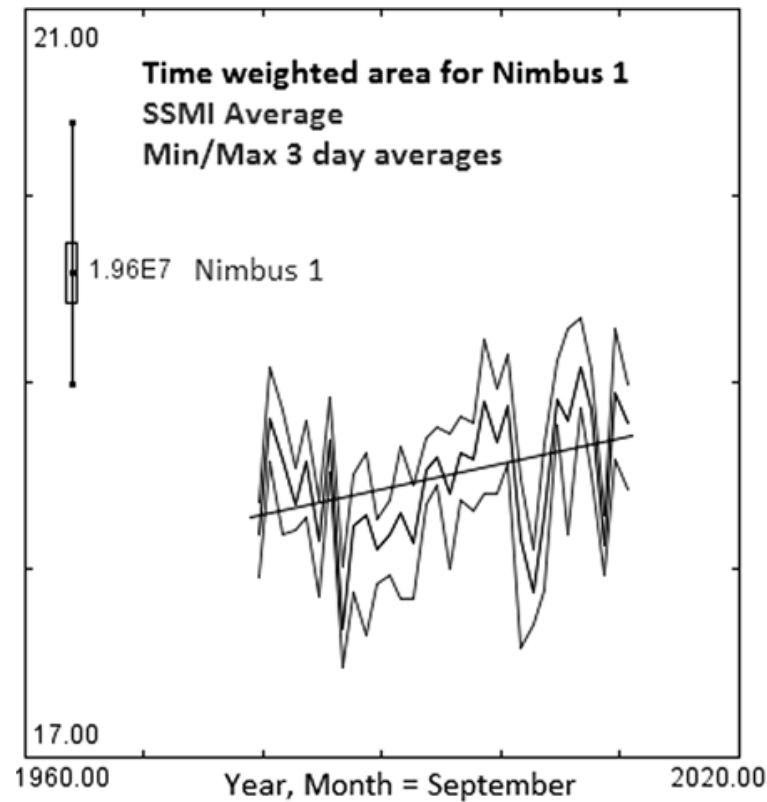

Fig. 5. Comparison of SSM/I September Antarctic ice extent with Nimbus I 1964 result. The ranges for the SSM/I are the 1 standard deviation of the 3-day means. The extremes for the 1964 data are the averages of all the maximums or minimums in each longitude bin. The box range represents \pm one standard deviation each bin average.

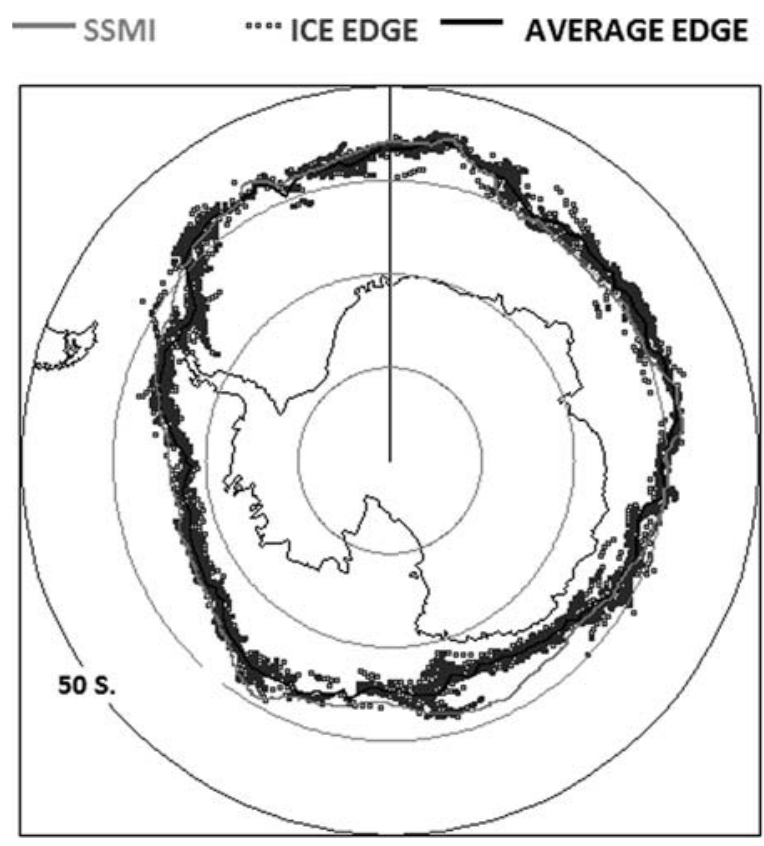

Fig. 6. Map of Antarctic ice edges for August 1966 with SSM/I climatology in green. Each red dot represents one ice edge determination.

August 1966 estimate fell well below the passive microwave record's minimum range. The Nimbus II ice extent of 15.9 million $\mathrm{km}^{2}$ is 2.2 million $\mathrm{km}^{2}$ lower than the passive microwave 1979-2000 average of 18.1 million $\mathrm{km}^{2}$, and is 1.7 million $\mathrm{km}^{2}$ lower than any August extent from 1979 to 2012 (Fig. 6). It is also lower than any individual daily values in the passive microwave time series for August. The anomalously low extent is due to the Nimbus ice edge being observed further poleward than in the passive microwave data, especially near $170^{\circ} \mathrm{E}$.

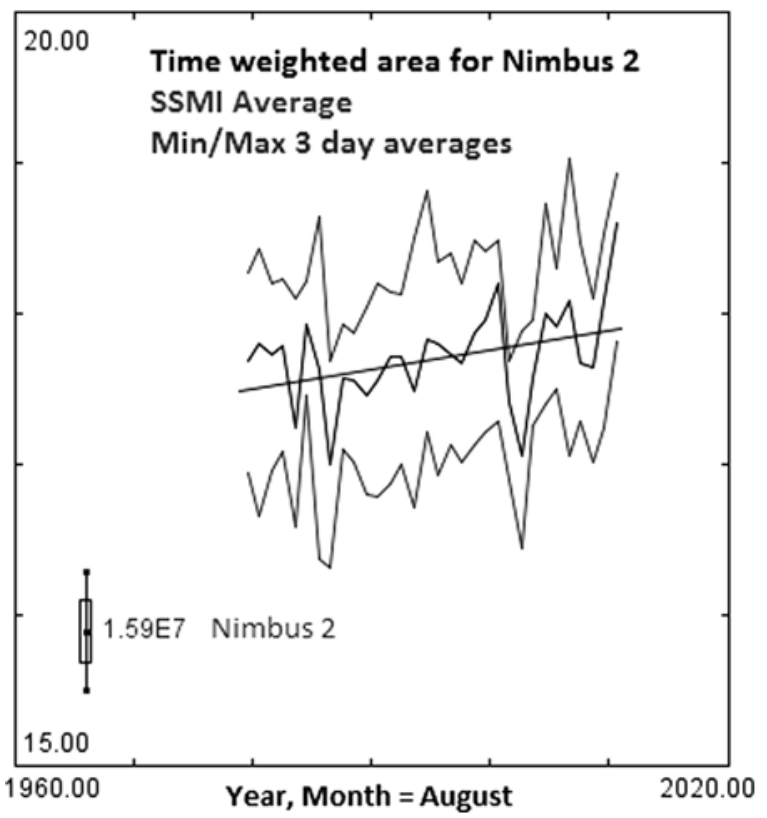

Fig. 7. Comparison of SSM/I August Antarctic ice extent with Nimbus II 1966 result. The range shown for the SSM/I data (1979-2013) is the standard deviation of the daily areas.

The fact that our August 1966 is such an outlier indicates potential issues in the Nimbus August data. In addition, the drop in extent from July to August is not seen in the passive microwave record and is not physically likely. This issue may be related to the data quality, the effect of the timing of the imagery on the monthly composite estimate, limitations in the manual analysis, or other factors. AVCS data is not available for September, the month when the Antarctic typically reaches its maximum. On the other hand, in the 1972 analysis of the 1966 Nimbus II data, Sissala [14] reported an even lower August ice extent of 15.17 million $\mathrm{km}^{2}$.

One potential explanation comes from the intra-month variability of the ice cover during August. Notice in Fig. 7 that there is significant variation in passive microwave ice extent in August, much more than in September. This is because the ice extent is still increasing in August as freezing occurs. So temporal sampling gaps or biases (i.e., sampling more early in the month vs. late in the month) can potentially bias a monthly composite estimate. Near the time of maximum extent in September both freezing and melting are occurring so there is less largescale daily change and the potential for a sampling bias will be smaller. Qualitatively, we do see the high daily variability the Nimbus II data for August 1966. There is not significant variability in the Nimbus I 1964 data in September, due in part, to the shorter 3-week record.

Unfortunately, we have been able to uncover any corroborating information on Antarctic sea ice in 1964 or 1966, including any data or imagery from US Navy aircraft over-flights [15]. There are a few other potential sources of satellite data from this time. The Soviet satellite Kosmos 44, 45 and 46 missions flew in August and September of 1964 [16], however the continuing existence of this data is in doubt. There was considerable DMSP data captured in the 1960s. Unfortunately, the Air Force indicated that all the DMSP imagery from the 


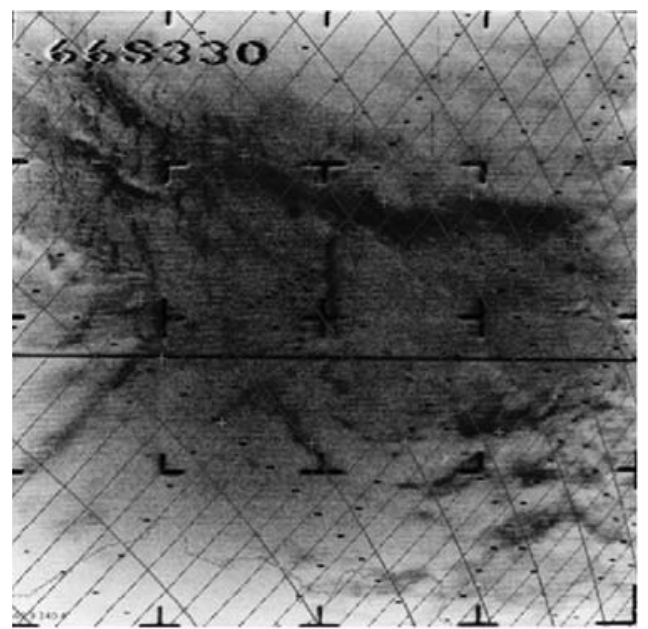

Fig. 8. August 1964, Nimbus I Antarctic AVCS image of the same general area as the Wendell Polynya seen the 1974-1976 Nimbus V ESMR data. Note the abundance leads and fractures.

1960s was destroyed and reclaimed for its silver content after it was analyzed (2010, personal communication, Dennis Hobson, DAFC Deputy Chief, Operational Capability Requirements Division HQ AFWA/A5R). Two 1964 Argon K5 satellites collected data from June-July and August-September 1964 respectively, but only a portion of the data is currently available [17] and will require further investigation. A 1963 Argon K5 dataset was recently reprocessed to produce an image of the Antarctica continental edge. This data may have potential for sea ice extent information as well [18]. The Wendell polynya seen in the 1974-1976 ESMR data did not appear in the Nimbus I or II data, however the 1964 data reveals numerous fractures and leads seen the same area as this polynya (Fig. 8).

\section{SUMMARY}

This study presents a method to calculate a composite monthly sea ice extent from the AVCS visible sensor on Nimbus satellites that were in orbit starting in 1964. Estimates from Nimbus I and Nimbus II for September 1964 and May-August 1996 respectively found anomalous Antarctic sea ice extents in both 1964 and 1966. The extent of sea ice around Antarctica was larger in September 1964 than in any September measured since (1973-1976 and 1979-2012) [1], [2], [11]. Even including the error bar, the 1964 results are outside the range of recent data, though 2012, a record high in the passive microwave record is on the outer range of the Nimbus estimate error bars. In 1966, extent was within 1973-2012 levels during May-June, but the August 1966 Antarctic extent was lower than any other August in the satellite record [4], [12], [13]. This potentially indicates an issue with August 1966 imagery. However, qualitative evaluation of the imagery and previous analysis of the imagery [14] appear to verify our estimate. Even accounting for the seasonality difference of $3.8 \times 10^{6} \mathrm{~km}^{2}$ between August and September, the sea ice change between winter 1964 and 1966 is unprecedented in the Antarctic climate record. To put this in perspective, the unusual decrease in sea ice extent between 1973 and 1976 was only $2.17 \times 10^{6} \mathrm{~km}^{2}$
[12]. Future analysis of the HRIR data may yield an estimate for September-November 1966 for improved comparisons.

In addition to the Nimbus data, we are attempting to recover the polar orbiting TIROS 9 and 10 visible data from film from 1965 and 1966 to fill in some temporal gaps. Scanning of the data is straight forward, but the documentation and metadata is very limited so navigation of the images will be difficult. These film images do not contain any time stamps; however the time of the start of the orbit is generally available so interpolation with selected feature identification may enable navigation that is accurate enough for the data to be useable.

In the future, an analysis using the same methods developed for this study on post-1973 DMSP visible data and comparing it with Nimbus 5 ESMR data from the same temporal range will further test the validity of this methodology. As seen from the sea ice examples, preservation of the early Nimbus data can be a valuable climate data record for observing important climate change indicators. In addition to extending the length of the 1979-2011 passive microwave sea ice records by as much as $50 \%$ (16 years), this data could be used for characterizing the Earth's climate and model validation for other parts of the globe including: sea surface temperatures, cloud fraction, hurricane, and potentially some land surface characteristics. These data will be available in NetCFD format from NSIDC in the summer of 2013.

\section{ACKNOWLEDGMENT}

The authors wish to thank the reviewers of this manuscript, whose comments significantly improved its quality. We also thank students Carl Gallaher and Alex Calder for their help scanning and documenting the data.

\section{REFERENCES}

[1] F. Fetterer, F. K. Knowles, W. Meier, and M. Savoie, Sea Ice Index. National Snow and Ice Data Ctr., Boulder, CO, USA, 2009, Digital media.

[2] H. J. Zwally, J. Comiso, C. Parkinson, W. Campbell, F. Carsey, and P. Gloersen, Antarctic Sea Ice, 1973-1976: Satellite Passive-Microwave Observations. NASA Special Publication 459, 1983.

[3] M. Tschudi, C. Fowler, J. Maslanik, and J. Stroeve, "Tracking the movement and changing surface characteristics of Arctic Sea Ice," IEEE J. Sel. Topics Appl. Earth Observ. Remote Sens., vol. 3, no. 4, pt. 1, pp. 536-540, 2010.

[4] C. Parkinson and D. J. Cavalieri, "Antarctic sea ice variability and trends," The Cryosphere, vol. 6, pp. 871-880, 2012, 10.5194/tc-6-8712012.

[5] Nimbus Program History. NASA Goddard Space Flight Center, 2004.

[6] Allied Research, The Nimbus II User's Guide. ARACON Geophysics Company, NASA Goddard Space Flight Center, National Archives Accession Number N67 12989, 1966.

[7] J. F. Moses and J. J. Bedet, "The value of cloud top and surface temperature observations from the 1966 Nimbus II high resolution infrared radiometer historical data record," in 2008 AGU Fall Conf., 2008.

[8] D. Gallaher, G. G. Campbell, W. Meier, and J. Moses, "Nimbus satellite data rescue project for Sea Ice extent: Preliminary results from September 1964, 1966, and 1969," in 2011 AGU Fall Conf., 2011.

[9] Y. Xuezhi and D. Clausi, "Evaluating SAR sea ice image segmentation using edge-preserving region-based MRFs," IEEE J. Sel. Topics Appl. Earth Observ. Remote Sens., vol. 5, no. 5, pp. 1383-1393, 2012.

[10] W. N. Meier, D. Gallaher, and G. G. Campbell, "New estimates of arctic and antarctic sea ice extent during September 1964 from recovered Nimbus I satellite imagery," The Cryosphere Discussions, 2012, no. tc-2012-187.

[11] M. Predoehl, "Antarctic pack ice: Boundaries established from Nimbus I pictures,” Science, vol. 153, no. 3738, pp. 861-863, 1966. 
[12] D. J. Cavalieri, C. L. Parkinson, and K. Y. Vinnikov, "30-year satellite record reveals contrasting arctic and antarctic decadal sea ice variability," Geophys. Res. Lett., vol. 30, no. 18, 2003, 10.1029/2003GL018031.

[13] National Snow and Ice Data Center, "Poles apart: A record-breaking summer and winter," The Cryosphere Discussions, 2013, in press.

[14] J. Sissala, R. Sabantini, and H. Ackermann, "Nimbus satellite data for polar ice survey," Polar Record, vol. 16, no. 102, pp. 367-373, 1972.

[15] USGS Earth Explorer, Antarctic Single Frames. [Online]. Available: http://earthexplorer.usgs.gov/ Accessed Oct. 2, 2012.

[16] J. McDowell, Launch Log, Jonathan's Space Page [Online]. Available: http://planet4589.org/space/log/launchlog.txt Accessed Dec. 21, 2009.

[17] EROS Data Center Declassified Satellite Imagery Products, 1995 [Online]. Available: http://eros.usgs.gov/\#/Find_Data/Products_and_Data_Available/Declassified_Satellite_Imagery_-_1

[18] K. Kim, K. C. Jezek, and H. Liu, "Orthorectified image mosaic of Antarctica from 1963 Argon satellite photography: Image processing and glaciological applications," Int. J. Remote Sens., vol. 28, no. 23, pp. 5357-5373, 2007.

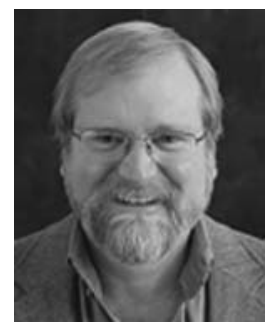

David W. Gallaher received the B.S. degree from the University of Illinois, Urbana-Champaign, IL, USA, in 1979 and the M.S. degree from Northern Arizona University, Flagstaff, AZ, USA, in 1984.

$\mathrm{He}$ has more than 30 years experience in geosciences, IT technology, and remote sensing. He has been at the National Snow and Ice Data Center in Boulder, CO, USA, since 2007 as the Technical Services Manager and Nimbus project Principle Investigator. Previously, he served in a variety of remote sensing roles in the public and private sectors.

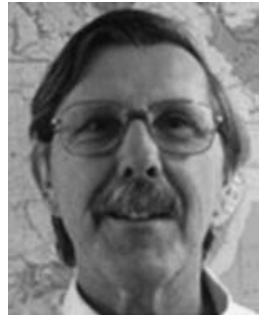

G. Garrett Campbell received the B.A. degree from Thiel College, Greenville, PA, USA, in 1970, the M.S. degree from Carnegie-Mellon University, Pittsburgh, PA, USA, in 1972, and the Ph.D. degree from Colorado State University, Fort Collins, CO, USA, in 1981.

He has been a Research Associate at the National Snow and Ice Data Center, University of Colorado, Boulder, CO, USA, since 2011. His research focuses on automated software system to collect and process Satellite data. He was a Research Associate at the Cooperative Institute for Research in the Atmosphere (CIRA) at Colorado State University from 1985 to 2007 .

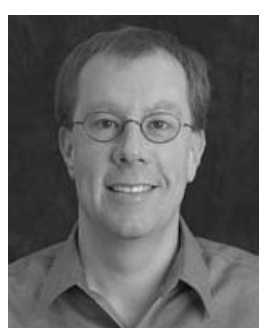

Walter N. Meier received the B.S. degree from the University of Michigan, Ann Arbor, MI, USA, in 1991 and the M.S. and Ph.D. degrees from the University of Colorado, Boulder, CO, USA, in 1992 and 1998, respectively.

He joined the NASA Goddard Space Flight Center in August 2013 as a research scientist in the Cryospheric Sciences Branch. His research focuses on satellite retrievals of sea ice characteristics, particularly from passive microwave radiometers. From 2003 to 2013, he was at the National Snow and Ice Data Center, Boulder, CO, USA, as the lead scientist for sea ice products. He was an Adjunct Assistant Professor at the U.S. Naval Academy, Annapolis, MD, USA, from 2001 to 2003 and a visiting scientist at the U.S. National Ice Center, Suitland, MD, USA, from 1999 to 2001. He is the Vice-Chair of the Cryosphere Working Group of the International Arctic Science Committee and a member of the WCRP Climate and Cryosphere Sea Ice Working Group. 